\title{
Low-Cost Printed Flexible Antenna by Using an Office Printer for Conformal Applications
}

\author{
Kashif Nisar Paracha, ${ }^{1}$ Sharul Kamal Abdul Rahim, ${ }^{1}$ Hassan Tariq Chattha $\mathbb{D}{ }^{2}$ \\ Saqer Saleh Aljaafreh, ${ }^{3}$ Sabih ur Rehman $\mathbb{D}^{4},{ }^{4}$ and Yew Chiong Lo $^{5}$ \\ ${ }^{1}$ Wireless Communication Centre, Universiti Teknologi Malaysia, Johor Bahru, Malaysia \\ ${ }^{2}$ Department of Electrical Engineering, Faculty of Engineering, Islamic University of Madinah, Al-Madinah, Saudi Arabia \\ ${ }^{3}$ Department of Electrical Engineering, Mu'tah University, Mu'tah, Jordan \\ ${ }^{4}$ Charles Sturt University, Bathurst, NSW, Australia \\ ${ }^{5}$ Faculty of Engineering, Multimedia University, Cyberjaya, Malaysia
}

Correspondence should be addressed to Hassan Tariq Chattha; chattha43@hotmail.com

Received 24 August 2017; Revised 17 November 2017; Accepted 6 December 2017; Published 14 February 2018

Academic Editor: Xuejun Lu

Copyright (c) 2018 Kashif Nisar Paracha et al. This is an open access article distributed under the Creative Commons Attribution License, which permits unrestricted use, distribution, and reproduction in any medium, provided the original work is properly cited.

\begin{abstract}
A low-cost inkjet printing method for antenna fabrication on a polyethylene terephthalate (PET) substrate is presented in this paper. An office inkjet printer is used to have desired patterns of silver nanoparticle ink on the PET substrate without any postprocessing. Silver nanoparticle ink cures instantly as soon as it is ejected from the printer on a chemically treated PET substrate. The thickness of the silver nanoparticle layer was measured to be $300 \mathrm{~nm}$ with a sheet resistance of as low as $0.3 \Omega / \mathrm{sq}$ and a conductivity around $1.11 \times 10^{7} \mathrm{~S} / \mathrm{m}$ with single layer deposition. A coplanar waveguide- (CPW-) fed Z-shape planar antenna on the PET substrate achieved the measured radiation efficiency of $62 \%$ and the IEEE gain of $1.44 \mathrm{dBi}$ at $2.45 \mathrm{GHz}$. The printed antenna is also tested in bending conditions to ascertain its performance for the Internet of things (IoT) conformal applications for the future $5 \mathrm{G}$ network.
\end{abstract}

\section{Introduction}

As per the vision of IMT-2020 for the future $5 \mathrm{G}$ network, the cost of Internet of things (IoT) devices needs to be reduced to as low as 5 dollars per unit [1]. To reduce the cost of these IoT devices, there is a dire need of a low-cost fabrication process. The production of low-cost devices is being revolutionized by the invention of inkjet printing of functional materials like polymers/nanocomposites, carbon nanotubes, graphene, and most recently molybdenum disulfide $\left(\mathrm{MoS}_{2}\right)$ nanosheets [2]. These materials are being used to fabricate transistors, antennas, sensors, light-emitting diodes, and many other printable devices [3]. Out of these, silver nanoparticle (AgNP) ink has been extensively used to deposit a thin metallic film on various substrates due to its wellknown high conductivity and being relatively low cost compared to other noble metals such as gold and platinum [4]. However, the printing of the antenna using the commonly used Dimatix printer 2800 series requires a subsequent thermal sintering (annealing) process which not only makes the usage of many polymeric substrates like polyethylene terephthalate (PET) or polycarbonate impractical due to their low glass transition temperature $\left(100^{\circ} \mathrm{C}-200^{\circ} \mathrm{C}\right)$ but also makes the fabrication process become complex and time consuming [5]. Instead of heating the complete sample during the sintering process, more selective sintering techniques were also used by various researchers, including laser sintering, low-pressure argon plasma exposure, microwave radiation, and electrical and photonic sintering [6]. However, the fabrication process using these techniques requires expensive equipment and proper parameter control to avoid the damage to the substrate. Moreover, the commonly used 
TABLE 1: Comparison between the office inkjet printer and commercially Dimatix 2800 series.

\begin{tabular}{|c|c|c|}
\hline Properties & Dimatix printer 2800 series & Office inkjet printer with AgNP ink. \\
\hline Cost of the printer & Very expensive $>30,000 \$$ & Very cheap $<600 \$$ \\
\hline Cost of the ink & Expensive $>1000 \$$ & Cheap $<400 \$$ \\
\hline Postprocessing & $\begin{array}{c}\text { Annealing processes for } 4 \mathrm{hrs} \text { in an expensive } \\
\text { industrial oven }\end{array}$ & Instantly cured ink \\
\hline Preheating & Heating vacuumed platen up to $60^{\circ} \mathrm{C}$ & Not required \\
\hline Conductivity & $1.6 \times 10^{6} \mathrm{~S} / \mathrm{m}$ (single layers, at $200^{\circ} \mathrm{C}$ ) & $\begin{array}{c}1.11 \times 10^{7} \mathrm{~S} / \mathrm{m} \text { (single layer, at room } \\
\text { temperature) }\end{array}$ \\
\hline Annealing temperature & Up to $120^{\circ} \mathrm{C}$ for 10 hours & Instantly cured \\
\hline $\begin{array}{l}\text { Low-cost glossy paper and PET } \\
\text { substrate }\end{array}$ & Not possible & Possible \\
\hline Layer thickness & $450 \mathrm{~nm}$ & $300 \mathrm{~nm}$ \\
\hline Sheet resistance of a single layer & $9 \Omega /$ sq at $100^{\circ} \mathrm{C}$ after 1 hour & $0.3 \Omega / \mathrm{sq}$ at room temperature after $10 \mathrm{~min}$ \\
\hline
\end{tabular}

inkjet printer (e.g., DMP 2800 series) is too expensive to make this type of the fabrication process commercially viable. In [6-10], antennas for wearable and conformal applications are fabricated using an inkjet printer on flexible substrates like Kapton, resin-coated paper, and glossy paper achieving reasonable conductivity up to $1 e 10^{7} \mathrm{~S} / \mathrm{m}$, but, unfortunately, it involves a long sintering process at higher temperature, that is, $150^{\circ} \mathrm{C}$ for several hours. Although the conventional office printer has also been used for printing the radiating part of the antenna on glossy paper by using AgNP ink to reduce the fabrication cost of the antenna, it requires long annealing time to exhibit reasonable conductivity for the antenna applications [11]. Some commercially available instantly chemically cured paints and markers are also available to avoid the thermal sintering process, but the large silver nanoparticle size $(1 \mathrm{~mm})$ with uneven and high sheet resistance of up to $55 \Omega /$ sq limits their implementation as an instant prototyping technique [12-14]. Hence, the formation of an AgNP ink layer by an office inkjet printer is one of the viable additive fabrication techniques which offers the advantage of being compatible with low-cost roll-toroll processing [15].

In this letter, we are using an instantly cured silver nanoparticle ink using an office inkjet printer for antenna application. A coplanar waveguide- (CPW-) fed Z-shape antenna on a chemically treated PET substrate is printed using an office printer. The ink is compatible with conventional Brother's printers, and its conductivity for a single printed layer reaches to a value of $1.11 \times 10^{7} \mathrm{~S} / \mathrm{m}$ with $300 \mathrm{~nm}$ layer thickness. The electrical conductivity and morphology analyses are done to ascertain the effectiveness of our used technique for a low-cost antenna fabrication method. Moreover, antenna performance is evaluated by measuring the reflection coefficients, gain, and radiation pattern of the antenna.

\section{Characterizing the Printed Silver Ink Layer}

2.1. Instantly Chemically Cured AgNP Layer. The silver nanoparticle ink is a special ink to work on a chemically treated PET substrate. This special AgNP ink has been successfully implemented to make electric circuits on a flexible PET substrate [16]. After inkjet printing, the polymer-confined silver nanoparticles used in the Dimatix printer series need several hours of the heating process, called sintering, to exhibit reasonable conductivity. The invention of chemically cured conductive inks has opened a new era of inkjet printing technology enabling the use of office inkjet printers without any postprocessing of printed conductive layers [17]. Chemical curing of the AgNP ink in printed antenna fabrication requires special treatment of the surface of the substrate so that a conduction path could be formed instantly at room temperature [18]. The comparison between our low-cost printed technique and the commercially available Dimatix printer technique is done in Table 1.

2.2. Morphological Analysis. The morphological analysis is very crucial for the complete study of the newly proposed technique for antenna fabrication. An SEM image was used to evaluate the surface morphology of the printed silver nanoparticle layer and the distribution of the silver particles by using a field emission scanning electron microscope (FESEM) (Hitachi, SU8020) operating at $2 \mathrm{kV}$.

EDS spectrum, as shown in Figure 1, reveals strong signal in the silver region and confirms the formation of AgNPs along with some traces of chemicals like chloride $(\mathrm{Cl})$, carbon (C), and aluminium ( $\mathrm{Al})$.

As shown in the images in Figure 2, the silver nanoparticles are agglomerated just by using a chemical sintering method which eliminates the development of "hot spots" due to differences in the conductivity within the printed layer. The white spots appearing in Figure 2(b) are believed to be the impurities present in the ink.

The cross-sectional SEM image of the printed layer, as shown in Figure 3, taken on a $200 \mathrm{~nm}$ scale with $5 \mathrm{kV}$ ETH, shows the thickness of the AgNPs and PET substrate to be $300 \mathrm{~nm}$ and $125 \mu \mathrm{m}$, respectively.

One of the important factors for performance of the printed antenna is its roughness. As we know that the AC current does not flow in the whole conductor, it remains near the surface of the conductor, resulting in higher current density. Especially, when the roughness dimensions are comparable to the skin depth of the EM waves at the operating frequency, these losses are prominent [17]. The roughness 


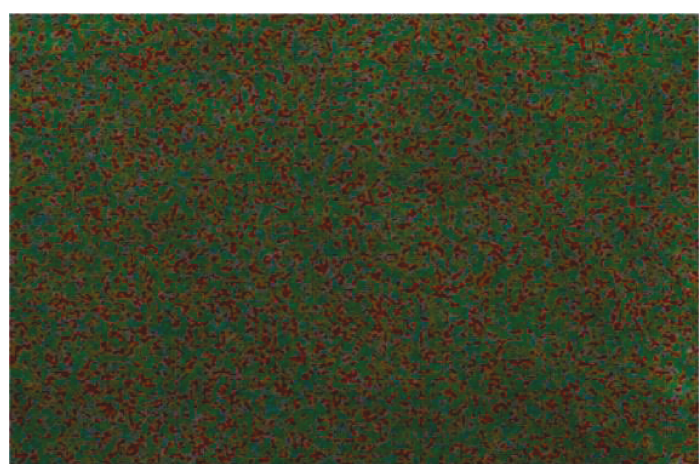

(a)

FIGURE 1: (a) SEM images of a nanoparticle layer for EDS analysis. (b) Quantitative spectrum of the contents of the particles in \%age.

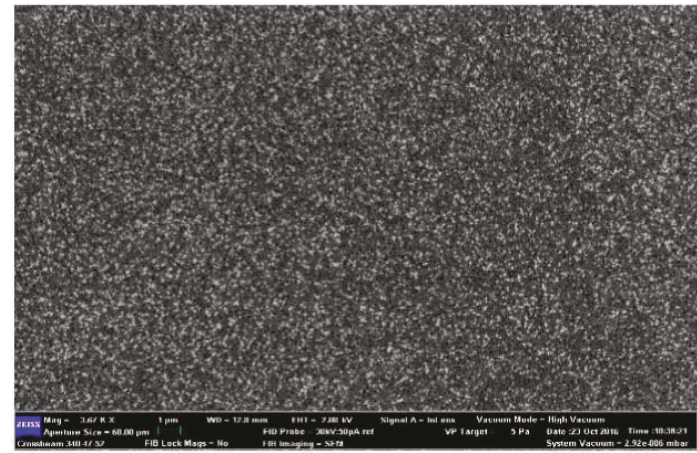

(a)

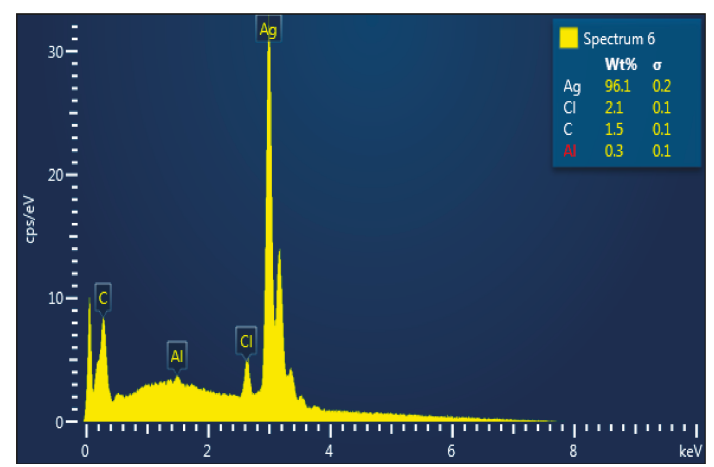

(b)

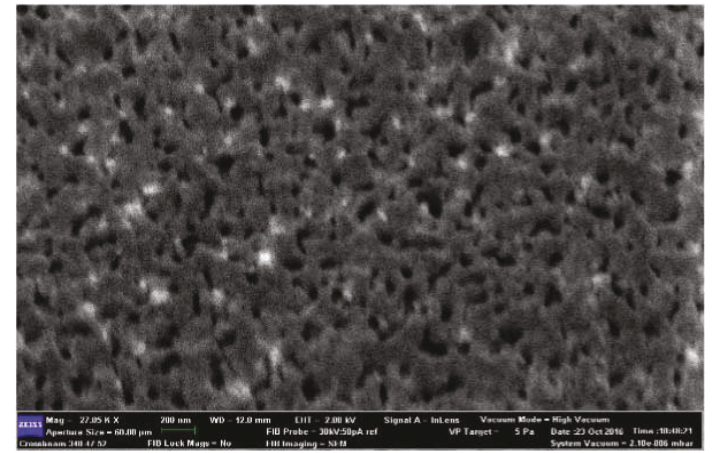

(b)

Figure 2: SEM image of the printed AgNP sample through FESEM with a voltage potential of $2 \mathrm{kV}$. (a) Scale bar=1 $\mu \mathrm{m}$. (b) Scale bar $=200 \mathrm{~nm}$.

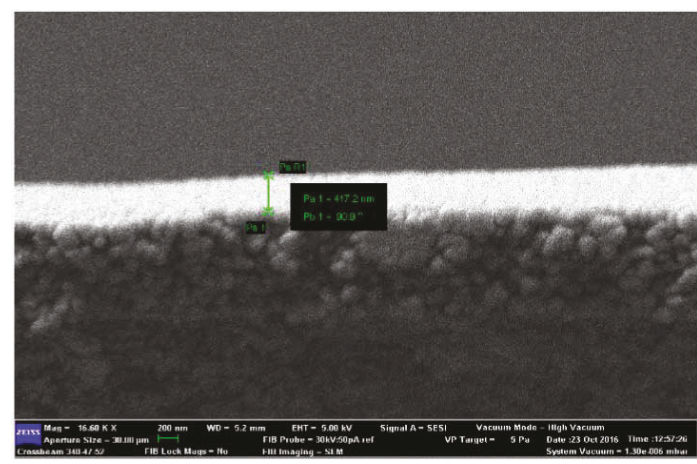

(a)

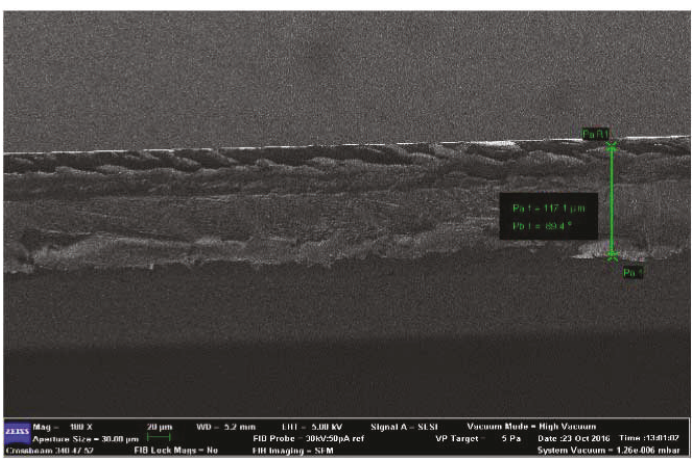

(b)

FIgure 3: Cross-sectional SEM images of the printed layer. (a) Scale bar $=200 \mathrm{~nm}$. (b) Scale bar $=20 \mu \mathrm{m}$.

of the printed layer has a direct impact on the AC resistance of the antenna which can be described by the following equations [19]:

$$
\begin{aligned}
R & =\frac{1}{w} \sqrt{\frac{\pi \mu f}{\sigma}} \\
c & =\left[1+\frac{2}{\pi} \tan ^{-1}\left\{1.4\left(\frac{\Delta}{\delta}\right)^{2}\right\}\right], \\
R_{\mathrm{s}} & =c \cdot R,
\end{aligned}
$$

where $\delta$ means the surface roughness, $c$ is the correction factor, and $R_{\mathrm{s}}$ is the surface resistance per unit length of the printed layer. To know the roughness of the printed AgNP layer, the height profile of the sample has been taken using the latest noncontact 3D surface profiler (Sensofar, Sneox) along the edge of the AgNP layer. As shown in Figure 4, the mean roughness $\left(S_{a}=0.299 \mu \mathrm{m}\right)$ and the root mean square roughness $\left(S_{q}=0.368 \mu \mathrm{m}\right)$ of the printed layer are quite reasonable to be used for antenna application since they are quite small as compared to the skin depth of the silver layer at $2.45 \mathrm{GHz}$, that is, $\delta=1.29 \mu \mathrm{m}$. 
m)
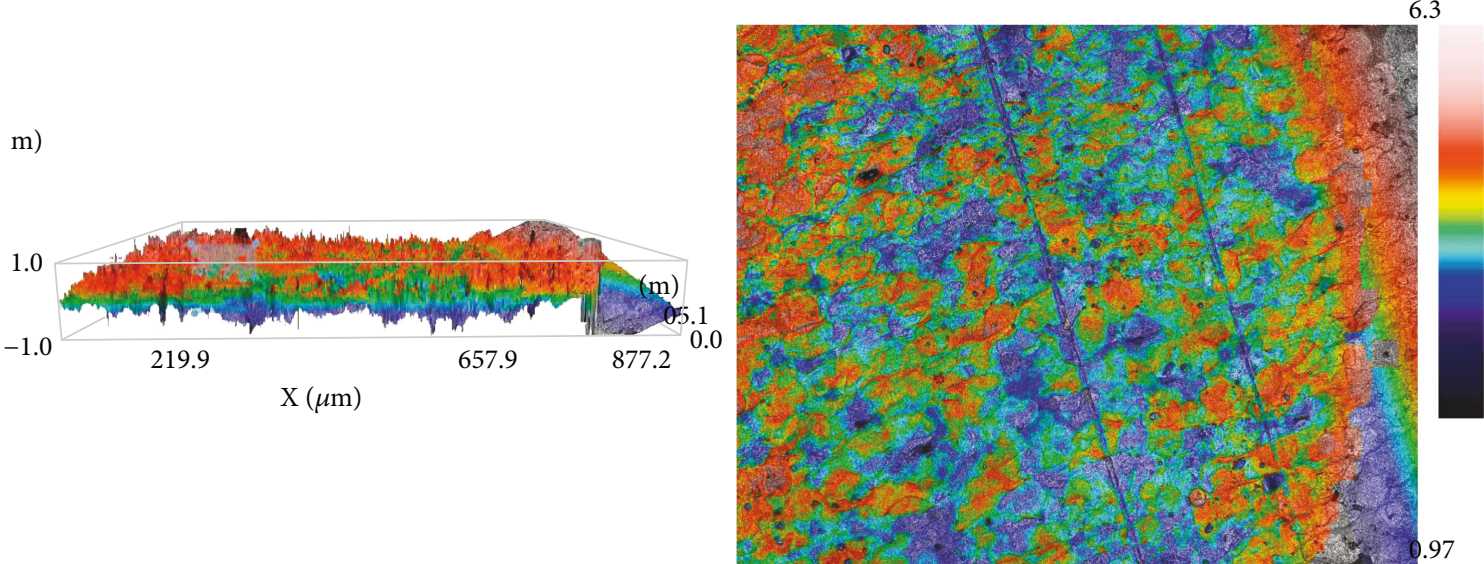

(a)

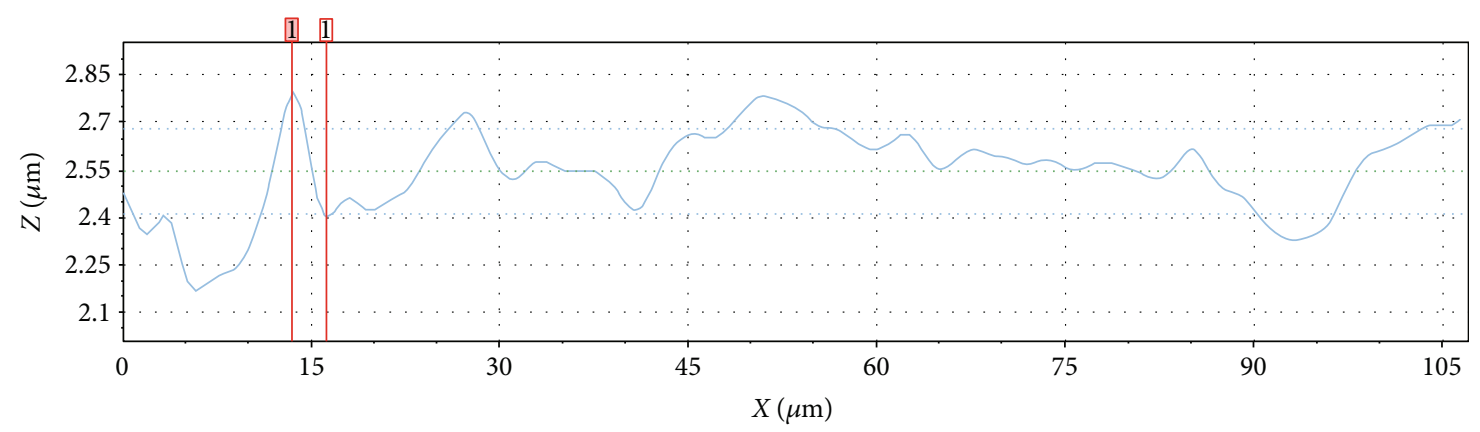

Notes

Distance $\quad \Delta L=-2.5808 \mu \mathrm{m} \Delta Z=395.72 \mathrm{~nm} \angle=8.72^{\circ}$

(b)

FIGURE 4: (a) Colored SEM image of the sample layer and 3D height profile. (b) 2D surface roughness graph.

By using (1), for the surface roughness of $0.299 \mu \mathrm{m}$ and the skin depth of $1.29 \mu \mathrm{m}$, the correction factor $(c)$ is calculated to be 1.045 . Hence, the increase in the AC resistance per unit length is only $4.5 \%$ with respect to a perfectly smooth surface (ideal). As we go towards higher frequency, for example, $6 \mathrm{GHz}$, the skin depth reduces, which results in surface roughness losses of only $11 \%$ (still acceptable). In addition, the average thickness observed from this profiler is well matched with FESEM measurements as shown in Figure 4.

\section{Fabrication and Results of a CPW-Fed Z-Shaped Antenna}

A CPW-fed Z-shaped antenna at $2.45 \mathrm{GHz}$ ISM band has been fabricated to ascertain the functionality of our new low-cost inkjet antenna fabrication technology as per the dimensions given in Figure 5. The dielectric characteristics of the substrate are measured using a dielectric probe. DAK-3.5 and the measured relative permittivity $\varepsilon_{\mathrm{r}}$ of the dielectric are found to be equal to 2.7 , and the loss tangent $\tan \delta$ is 0.135 . The gap between the ground and the feed line is $0.3 \mathrm{~mm}$, and rectangular slots in the Z-shape antenna are of equal size. Antenna design parameters are first optimized for the PET substrate based on simulations carried out using the CST microwave studio, and fabrication is done using

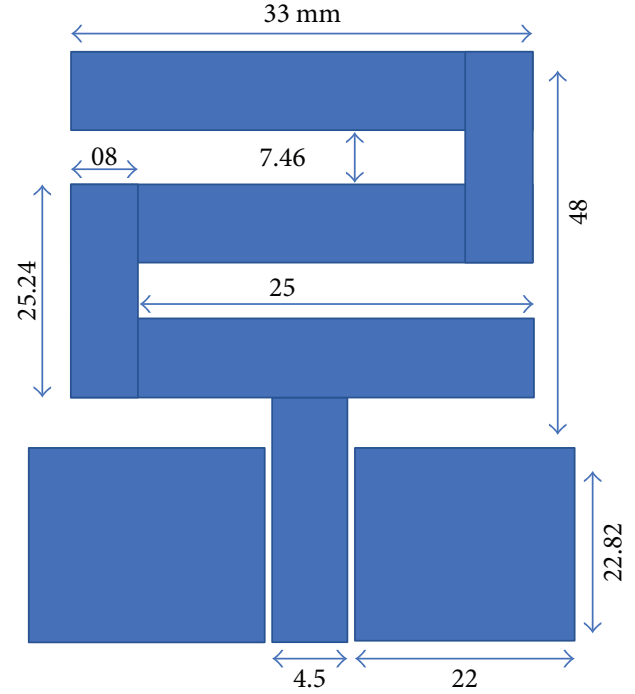

Figure 5: The dimensions of the CPW-fed Z-shaped antenna.

commercial low-cost piezoelectric inkjet Brother's printer. To validate its functionality as a bent antenna for conformal application, we also performed a bending test by placing the antenna on a curved sample of foam with $30 \mathrm{~mm}$ and $40 \mathrm{~mm}$ bending radius as depicted in Figure 6(b). The coplanar 


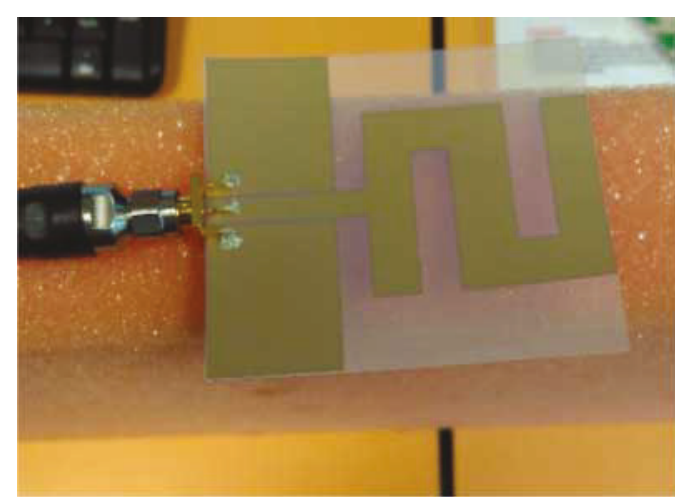

(a)

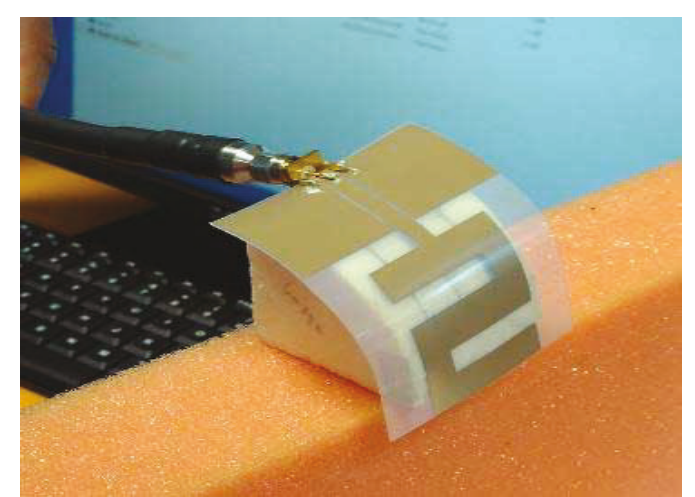

(b)

FIGURE 6: Fabricated Z-shape antenna by the proposed inkjet printer technique on the PET substrate. (a) Flat condition. (b) Bending condition (radius: $40 \mathrm{~mm}$ ).

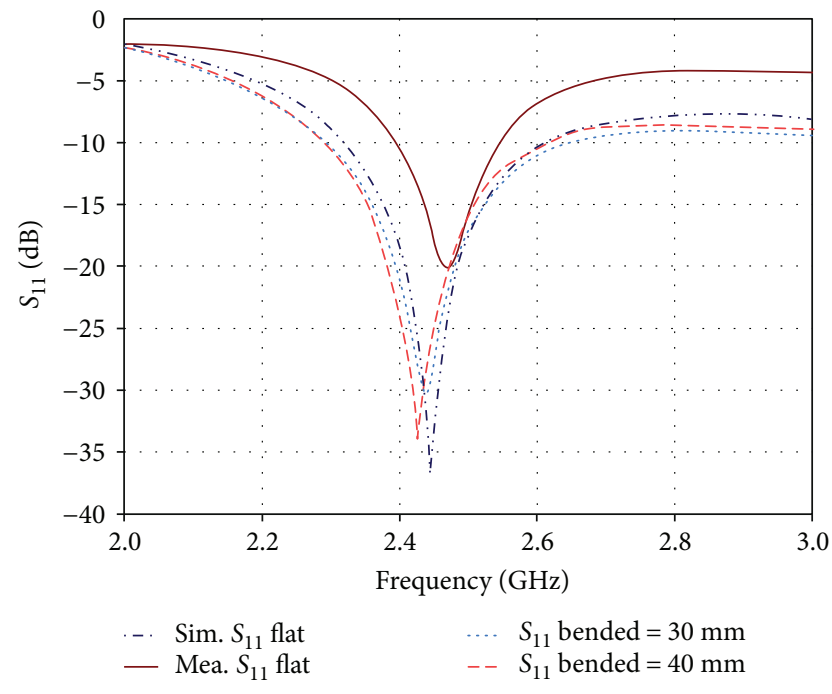

Figure 7: The reflection coefficient $S_{11}$ in $\mathrm{dB}$ of the Z-shaped antenna with and without bending conditions.

waveguide (CPW) configuration, where the radiator and the ground plane are printed on the same side of the substrate, is chosen for its simplicity and ease of fabrication in a roll-toroll production process. The printed CPW-fed Z-shape antenna is first printed by the office printer, and then the SMA connector was connected to the feed line. Due to higher soldering temperature $\left(150^{\circ} \mathrm{C}\right)$, the thermal soldering method cannot be used; hence, silver nanoparticle paint from $\mathrm{PELCO}^{\circledR}$ has been used to connect the SMA connector with the feed line of the antenna, as shown in Figure 6.

The conventional Brother printer MFC-J430W with AgIC ink cartridge model number 1000 has been used to print this antenna. A cartridge from AgIC Company comes with three containers filled with AgNP ink to be inserted in three holders of the inkjet printer. The size of the silver nanoparticle is around $20 \mathrm{~nm}$ in diameter. Due to its very small particle size, the dissolution of AgNPs is made possible in the chemical solution used for chemical sintering of the deposited layer and makes the ejection of the ink from the printer nozzle easy.

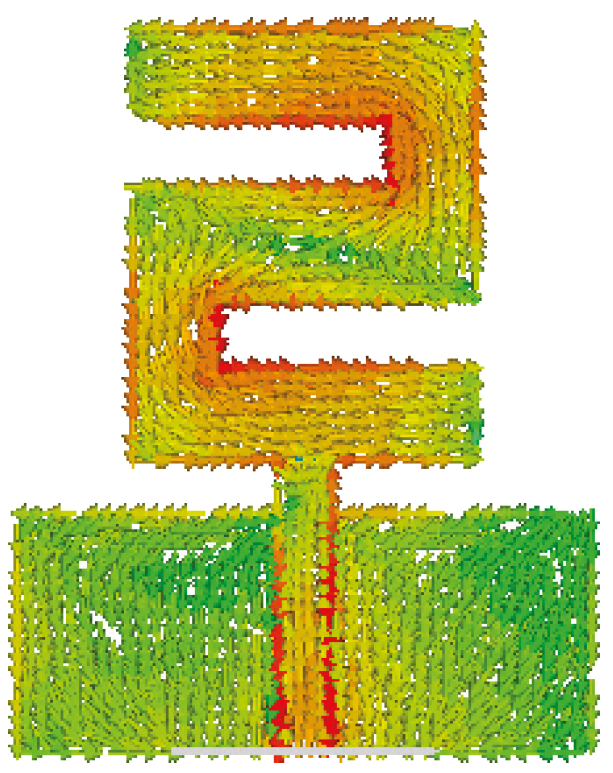

FIgURE 8: Simulated current distribution of the antenna at $2.45 \mathrm{GHz}$.

To verify our proposed technique, we evaluated the reflection coefficient of the antenna at flat and bending radii of 30 and $40 \mathrm{~mm}$ by attaching it on a foam. As shown in Figure 7, the antenna is performing quite well for both radius positions. These radius values are taken considering the normal radii of the human arms and legs. The measurements are performed using a 4-port Vector Network Analyzer (VNA) model N5242A PNA-X from Agilent Technologies. The results show that a good match of measured reflection coefficient is found not only with the simulated results in the ISM band $(2.45 \mathrm{GHz})$ in the flat shape but also after bending conditions. Since there is no heating process involved, the cracks cannot be observed in the printed layer after bending the antenna as reported in [8]. The measured conductivity of the printed layer is found to be around $1.11 \times 10^{7} \mathrm{~S} / \mathrm{m}(14.7 \%$ of the conductivity of the bulk silver) with single $300 \mathrm{~nm}$ layer thickness and $0.3 \Omega / \mathrm{sq}$ sheet resistance. The conductivity of the double printed layer is reported to be twofold with misalignment error 


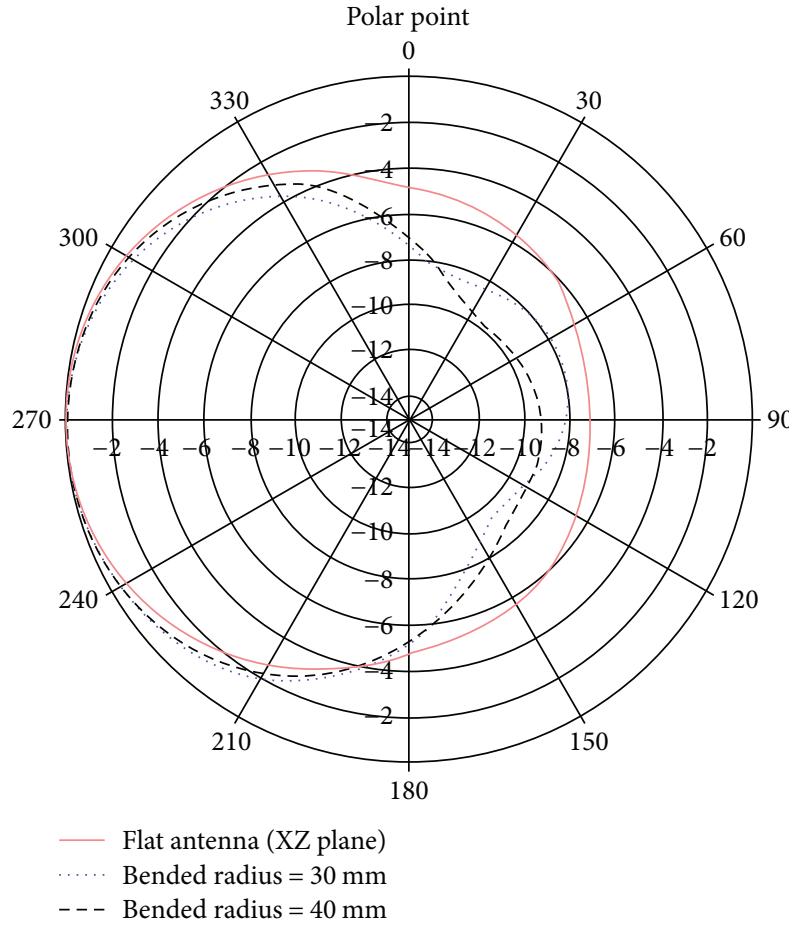

(a)

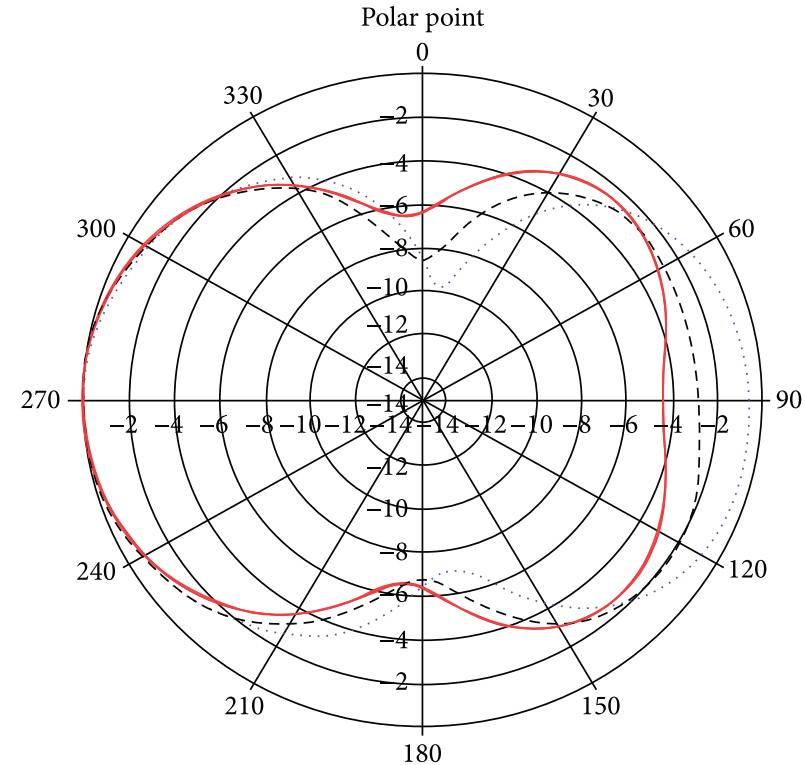

- Flat antenna (YZ plane)

Bended radius $=30 \mathrm{~mm}$

--- Bended radius $=40 \mathrm{~mm}$

(b)

FIGURE 9: Radiation patterns of the antenna with different bending radii of 30 and $40 \mathrm{~mm}$ : (a) XZ plane $\left(\phi=0^{\circ}\right)$ and $(\mathrm{b}) \mathrm{YZ}$ plane $\left(\phi=90^{\circ}\right)$.

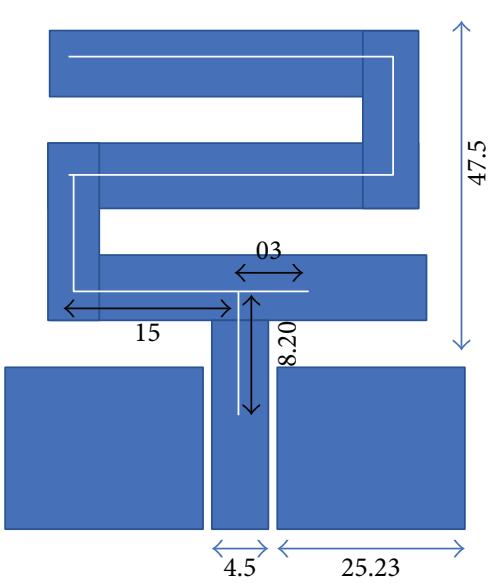

(a)

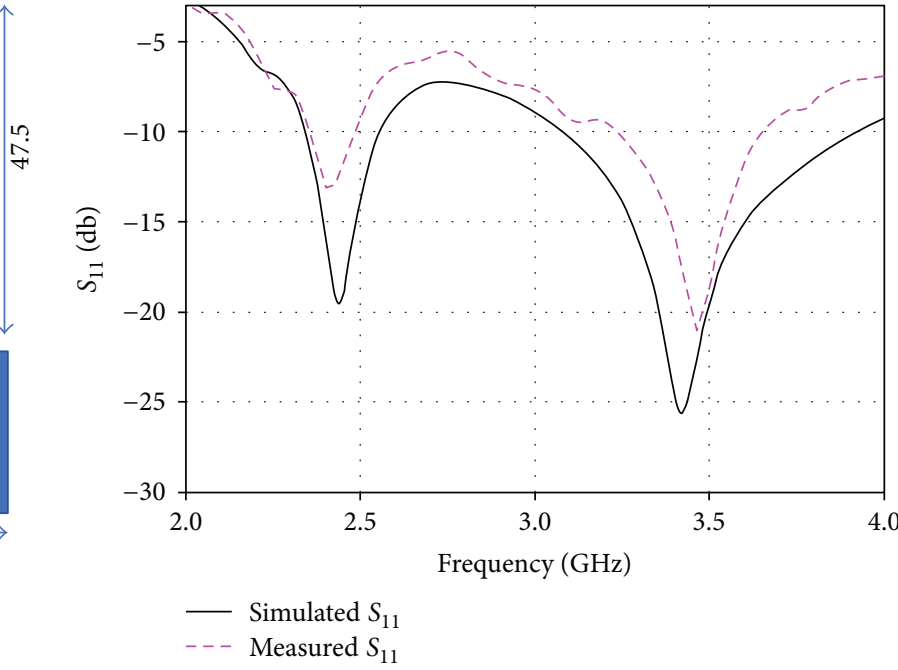

(b)

Figure 10: (a) The layout of the slotted Z-shaped antenna. (b) The reflection coefficient $S_{11}$ in dB of the slotted Z-shaped antenna.

up to $0.5 \mathrm{~mm}$ while using an off-the-shelf printer [16]. The behavior of the antenna is also studied through its current distribution at $2.45 \mathrm{GHz}$, as shown in Figure 8, where it is shown that good current density distribution exists along the edges as normally happening in the case of the patch antenna.

To see the performance of this antenna for different antenna parameters, the gain of this fabricated antenna is also measured. The maximum measured gain of the antenna is found to be $1.44 \mathrm{dBi}$ with more than $60 \%$ radiation efficiency.

To see the radiation performance of the antenna, the radiation patterns of this antenna in the flat and curved shapes at a frequency of $2.45 \mathrm{GHz}$ are plotted in Figure 9. The bending of the antenna results in slight widening of the radiation pattern for both $\mathrm{XZ}$ and $\mathrm{YZ}$ planes. Hence, our inkjet printed antenna can be used for both flexible and conformal applications. 


\section{Modified CPW-Fed Z-Shaped Antenna}

To check the validity of our printing technology for higher frequencies specially 5G, the CPW-fed Z-shaped antenna, presented above, is modified to cover a future expected $5 \mathrm{G}$ band, that is, $3.5 \mathrm{GHz}$. A slot of $0.5 \mathrm{~mm}$ thickness is etched in the middle of the zigzag path of the Z-shaped antenna, and then it is slightly optimized to work at our required frequency bands. The remaining dimensions of the etched slot are shown in Figure 10(a). The other dimensions of the proposed antenna are the same as those of the Z-shaped antenna shown in Figure 5 unless, otherwise, mentioned. The other parameters of the modified Z-shaped antenna are the same as shown in Figure 5. This designed antenna is fabricated, and the simulated and measured results of reflection coefficient $S_{11}(\mathrm{~dB})$ in the flat shape are shown in Figure 10(b). The measured results match reasonably well with the simulated ones.

\section{Conclusion}

A CPW-fed Z-shaped antenna is fabricated using low-cost printed fabrication techniques. An office inkjet printer using a special cartridge from AgIC, Japan, has been used during printing the antenna. The most prominent feature of this silver ink is that it dries out instantly at the room temperature. This chemically cured formation of the conduction path of the silver nanoparticles not only facilitates the usage of substrates of low glass transition temperature $\left(T_{\mathrm{g}}\right)$ but also eliminates the need of a prevalent expensive inkjet printer which employs expensive equipment and long postheating process. Moreover, the bending test has been performed to validate its functionality for conformal antenna applications. The surface morphology and height profile analyses of the printed layer are also executed. This proposed technique using an office inkjet printer should pave the path for easy and lowcost printing of the antennas for conformal applications.

\section{Conflicts of Interest}

The authors declare that they have no conflicts of interest.

\section{References}

[1] A. Osseiran, F. Boccardi, V. Braun et al., "Scenarios for 5G mobile and wireless communications: the vision of the METIS project," IEEE Communications Magazine, vol. 52, no. 5, pp. 26-35, 2014.

[2] D. J. Finn, M. Lotya, and J. N. Coleman, "Inkjet printing of silver nanowire networks," ACS Applied Materials \& Interfaces, vol. 7, no. 17, pp. 9254-9261, 2015.

[3] J. Hu, "Overview of flexible electronics from ITRI's viewpoint," in 2010 28th VLSI Test Symposium (VTS), pp. 84-84, Santa Cruz, CA, USA, 2010.

[4] J. Kim and W. S. Kim, "Stretching silver: printed metallic nano inks in stretchable conductor applications," IEEE Nanotechnology Magazine, vol. 8, no. 4, pp. 6-13, 2014.

[5] Y. Al-Naiemy, T. A. Elwi, H. R. Khaleel, and H. Al-Rizzo, "A systematic approach for the design, fabrication, and testing of microstrip antennas using inkjet printing technology," ISRN
Communications and Networking, vol. 2012, Article ID 132465, 11 pages, 2012.

[6] S. Ahmed, F. A. Tahir, A. Shamim, and H. M. Cheema, "A compact Kapton-based inkjet-printed multiband antenna for flexible wireless devices," IEEE Antennas and Wireless Propagation Letters, vol. 14, pp. 1802-1805, 2015.

[7] H. R. Khaleel, "Design and fabrication of compact inkjet printed antennas for integration within flexible and wearable electronics," IEEE Transactions on Components, Packaging and Manufacturing Technology, vol. 4, no. 10, pp. 17221728, 2014.

[8] H. F. Abutarboush, M. F. Farooqui, and A. Shamim, "Inkjetprinted wideband antenna on resin-coated paper substrate for curved wireless devices," IEEE Antennas and Wireless Propagation Letters, vol. 15, pp. 20-23, 2016.

[9] B. S. Cook and A. Shamim, "Inkjet printing of novel wideband and high gain antennas on low-cost paper substrate," IEEE Transactions on Antennas and Propagation, vol. 60, no. 9, pp. 4148-4156, 2012.

[10] H.-L. Kao, C.-L. Cho, X. Y. Zhang et al., "Bending effect of an inkjet-printed series-fed two-dipole antenna on a liquid crystal polymer substrate," IEEE Antennas and Wireless Propagation Letters, vol. 13, pp. 1172-1175, 2014.

[11] A. M. Mansour, N. Shehata, B. M. Hamza, and M. R. M. Rizk, "Efficient design of flexible and low cost paper-based inkjetprinted antenna," International Journal of Antennas and Propagation, vol. 2015, Article ID 845042, 6 pages, 2015.

[12] P. Bare, http://www.bareconductive.com/.

[13] C. C. Pen, October, https://www.chemtronics.com/p-693circuitworks-conductive-pen.aspx.

[14] Z. Li, H. Liu, C. Ouyang et al., "Recent advances in penbased writing electronics and their emerging applications," Advanced Functional Materials, vol. 26, no. 2, pp. 165-180, 2016.

[15] Z. Cui, C. Ma, Z. Chen et al., Printed Electronics: Materials, Technologies and Applications, John Wiley \& Sons, Singapore Pte. Ltd., 2016.

[16] Y. Kawahara, S. Hodges, B. S. Cook, C. Zhang, and G. D. Abowd, "Instant inkjet circuits: lab-based inkjet printing to support rapid prototyping of UbiComp devices," in Presented of the Proceedings of the 2013 ACM International Joint Conference on Pervasive and Ubiquitous Computing, pp. 363-372, Zurich, Switzerland, 2013.

[17] C. R. Garcia, H. H. Tsang, J. H. Barton, and R. C. Rumpf, "Effects of extreme surface roughness on 3D printed horn antenna," Electronics Letters, vol. 49, no. 12, pp. 734-736, 2013.

[18] K. Black, J. Singh, D. Mehta, S. Sung, C. J. Sutcliffe, and P. R. Chalker, "Silver ink formulations for sinter-free printing of conductive films," Scientific Reports, vol. 6, article 20814, 2016.

[19] D.-Y. Shin, Y. Lee, and C. H. Kim, "Performance characterization of screen printed radio frequency identification antennas with silver nanopaste," Thin Solid Films, vol. 517, no. 21, pp. 6112-6118, 2009. 


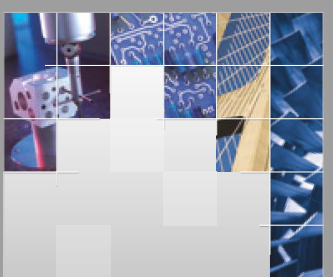

\section{Enfincering}
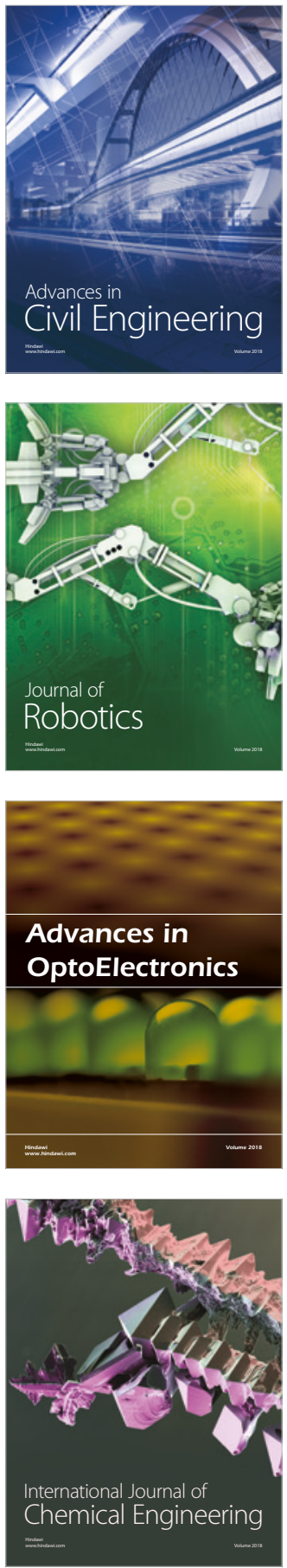

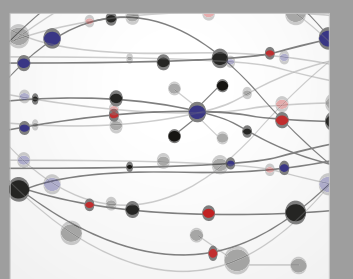

\section{Rotating \\ Machinery}

The Scientific World Journal

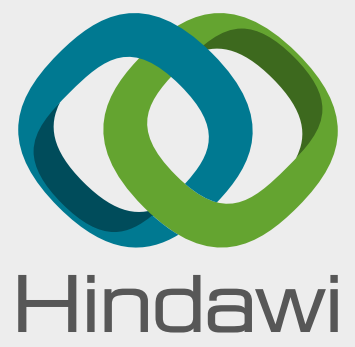

Submit your manuscripts at

www.hindawi.com
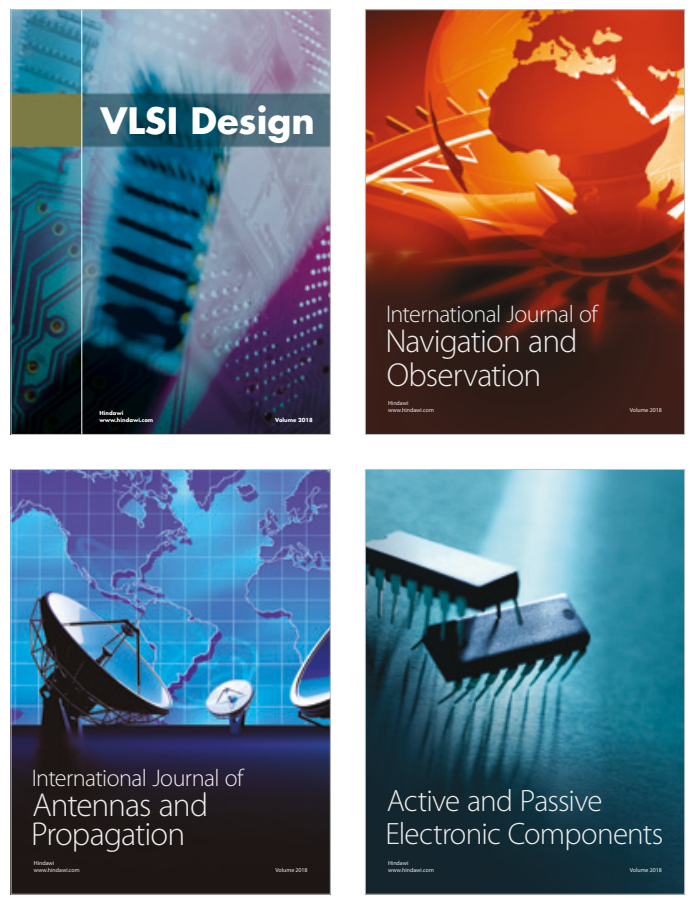
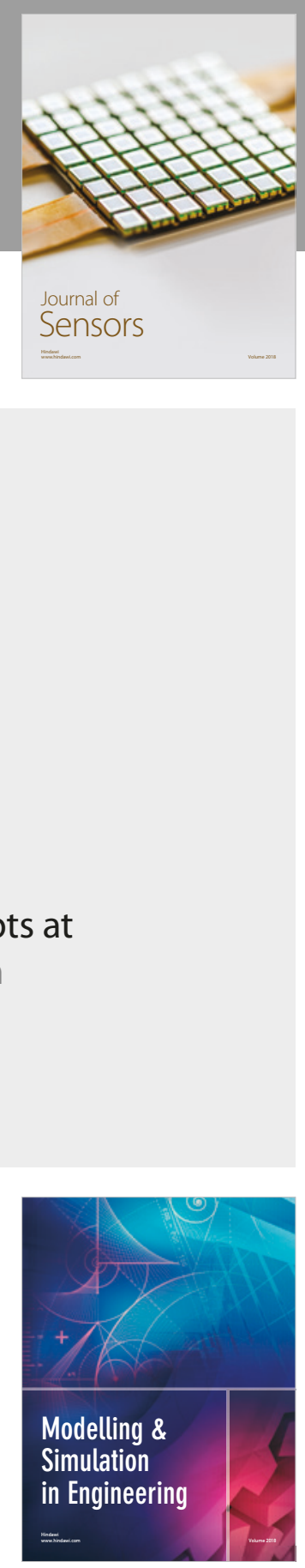

\section{Advances \\ Multimedia}
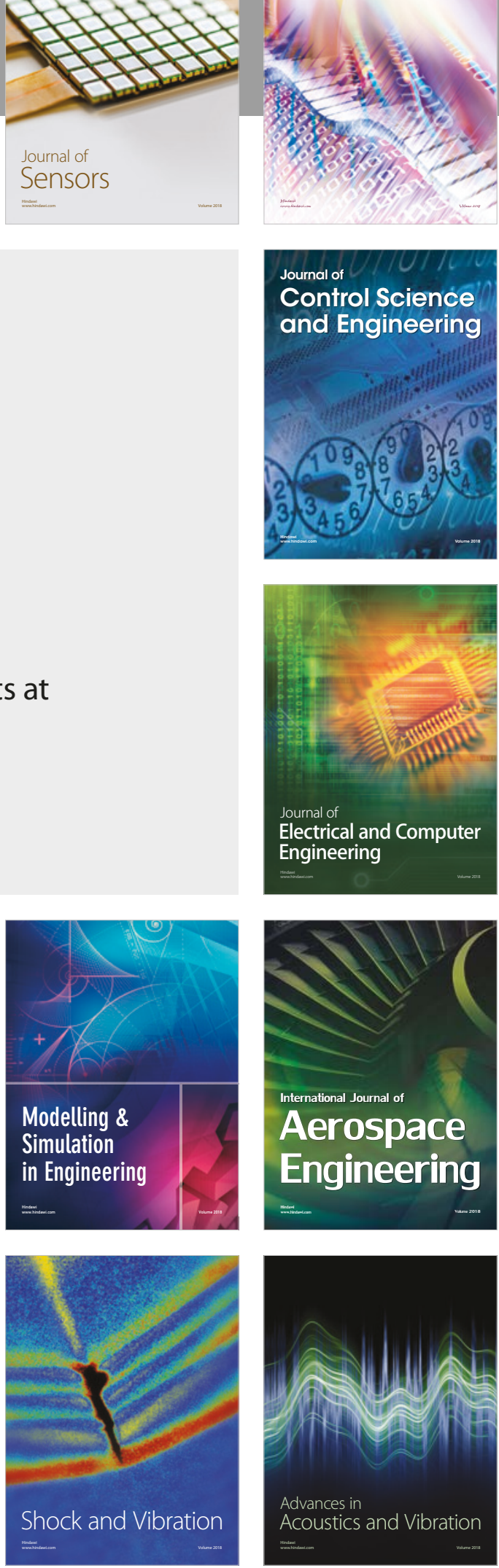